\title{
AETIOLOGY AND OUTCOME OF ACUTE KIDNEY INJURY IN TYPE 2 DIABETES PATIENTS
}

\author{
Fenny Korandiarkunnel Paul1, Mridulkumar Kannath ${ }^{2}$
}

${ }_{1}^{1}$ Senior Resident, Department of General Medicine, Government Medical College, Kozhikode, Kerala, India.

2Associate Professor, Department of General Medicine, Government Medical College, Kozhikode, Kerala, India.

\section{BACKGROUND}

ABSTRACT

Diabetes is the most important contributor to the growing burden of end stage renal disease, and patients with diabetes are also at a greater risk of requiring hospitalizations and experiencing acute kidney injury. Because of the morbidity and mortality ass ociated with acute kidney injury, it is important for primary care physicians to identify patients who are at a high risk of developing this type of injury and to implement preventive strategies. Though many studies have evaluated the development or progression of chronic kidney disease, only few studies have assessed the risk factors and outcomes of AKI in Type 2 diabetics. Hence, we conducted this study. Early recognition and appropriate management of acute kidney injury in hospitalized patients is one of the ways to curb the growing burden of end stage kidney disease in diabetics.

\section{MATERIALS AND METHODS}

We conducted a Cohort study to analyze the causes, recovery of renal function and mortality of AKI in 100 adult diabetic patients admitted in ICU and wards under the Dept. of Medicine and Nephrology in relation to age, sex, mean FBS, PPBS, electrolytes, blood urea and serum creatinine levels.

\section{RESULTS}

AKI was predominantly encountered in older males. Most common causes of acute renal failure were found to be infection and urinary tract obstruction. NSAID was most common cause of drug induced renal failure. $69 \%$ had a good outcome of which $10 \%$ had partial recovery and $59 \%$ had full recovery. $31 \%$ had poor outcome of which $10 \%$ went in for maintenance hemodialysis and $21 \%$ expired during the period of study.

\section{CONCLUSION}

Most common causes of renal failure in the study were found to be infection and urinary tract obstruction. Acute renal failure recovered in $69 \%$.

\section{KEY WORDS}

Acute Kidney Injury; Type 2 Diabetes; Infection.

HOW TO CITE THIS ARTICLE: Paul FK, Kannath M. Aetiology and outcome of acute kidney injury in type 2 diabetes patients. J. Evolution Med. Dent. Sci. 2018;7(47):5078-5083, DOI: $10.14260 /$ jemds/2018/1129

\section{BACKGROUND}

The incidence of diabetes mellitus in human population has reached epidemic proportions world-wide. It is estimated that ten years down the line, one in every five diabetics will be an Indian.(1) Diabetes mellitus is the single largest contributor to the growing prevalence of chronic kidney disease.(2) Progressive decline in renal function has been well described in patients with Type 2 diabetes mellitus, but few studies have assessed the risk of acute kidney injury in patients with Type 2 diabetes. So this study is planned to find out the aetiology and outcome of acute kidney injury in patients with Type 2 diabetes from a tertiary referral hospital in Kerala.

Acute kidney injury (AKI), formerly called acute renal failure (ARF), is commonly defined as an abrupt decline in renal function resulting in a reversible acute increase in nitrogenous waste products normally cleared by the kidneys.

'Financial or Other Competing Interest': None.

Submission 11-10-2018, Peer Review 04-11-2018,

Acceptance 10-11-2018, Published 19-11-2018.

Corresponding Author:

Mridulkumar Kannath,

Shreyas, Mudappattuthazham,

Karuvissery P. O.,

Kozhikode-673010, Kerala, India.

E-mail: mridulkumar.k@gmail.com

DOI: $10.14260 /$ jemds/2018/1129
Over the past few years, international guideline groups have attempted to establish consistent definitions and staging systems for AKI. Initially the RIFLE (Risk, Injury, Failure, Loss, End stage kidney disease) system was set up in 2004.(4) This was modified by the AKIN (Acute Kidney Injury Network) and further developed in 2012 by KDIGO (Kidney Disease: Improving Global Outcomes).(5,6,7) They work on levels of creatinine rise-

1. Increase in serum creatinine by $>0.3 \mathrm{mg} / \mathrm{dl}$ within 48 hours.

2. Increase in creatinine to $>1.5$ times baseline, which is known/ presumed to have occurred within the past 7 days.

3. A drop in urine output to $0.5 \mathrm{ml} / \mathrm{kg} /$ hour for 6 hours in adults.

The stage of AKI affects both management recommendations and prognosis, hence the importance of defining consistent stages. KDIGO defines stage 1, 2 and 3 through increasing rises in creatinine levels and drop in urinary output-

1. Increase in serum creatinine 1.5-1.9 times baseline or > $0.3 \mathrm{mg} / \mathrm{dl}$ increase.

2. Increase in serum creatinine 2.0-2.9 times baseline.

3. Increase in serum creatinine 3.0 times baseline or Increase in serum creatinine to $>4 \mathrm{mg} / \mathrm{dl}$. 


\section{Aims and Objectives}

1. To study the aetiology of acute kidney injury in patients with type 2 diabetes.

2. To study the outcome of acute kidney injury in type 2 diabetic patients.

\section{MATERIALS AND METHODS}

The present study was undertaken to identify the causes and to study the outcome of acute kidney injury in Type 2 diabetic patients.

\section{Study Design \\ Cohort study.}

\section{Study Setting}

ICU and wards under the Dept. of Medicine and Nephrology, Govt. Medical College Hospital, Kozhikode

\section{Study Population}

Type 2 diabetic patients with acute kidney injury irrespective of age and gender.

\section{Inclusion Criteria}

Type 2 diabetic patients 30 years or above, irrespective of gender, diagnosed to have acute kidney injury using KDIGO criteria, admitted to ICU or wards under the Dept of Medicine and Nephrology, Govt. Medical College, Kozhikode.

\section{Exclusion criteria}

Patients with preexisting renal disease and those who received renal transplantation.

\section{Study Duration \\ 1 year.}

\section{Data Collection}

Type 2 diabetic patients admitted in the ICU and wards under Medicine and Nephrology department, Govt. Medical College, Kozhikode were evaluated in detail after taking prior consent. Evaluation includes detailed history taking and physical examination. Acute kidney injury will be assessed on the basis of their serum creatinine and/or urine output fulfilling the KDIGO criteria.

\section{Outcome is assessed by}

1. Fully recovered - Creatinine has returned to baseline value.

2. Partial recovery - Less than $50 \%$ improvement in creatinine values.

3. Dialysis dependent.

4. Mortality - defined as patients expiring during the hospital stay.

\section{Statistical Analysis}

Results were presented as frequency and percentages for Categorical variables and mean+/- SD for continuous variables. Statistical calculations were done using Chi-square tests for categorical data and on independent t-test. For continuous data. $\mathrm{P}<0.05$ was considered significant. The calculations were carried out using SPSS (Statistical Package for the Social Sciences).

\section{RESULTS}

The study was conducted in a total of 100 diabetic patients who developed acute kidney injury. There were 64 males and 36 females. The aetiology and outcome of acute kidney injury in the above patients were found out. Blood urea, serum creatinine, serum electrolytes, fasting and post-prandial blood sugar, WBC count, platelet count and haemoglobin were included as the baseline parameters.

1. Percentage distribution of age of patients included in the study.

\begin{tabular}{|c|c|}
\hline Age group & Percent \\
\hline$<50$ & 21 \\
\hline $50-59$ & 37 \\
\hline $60-69$ & 30 \\
\hline$>=70$ & 12 \\
\hline \multicolumn{2}{|c|}{ Table 1 } \\
\hline
\end{tabular}

Most of the patients were in the age group of 50-59 years with $37 \%$ incidence

2. Percentage distribution of various drugs leading to the development of acute kidney injury in diabetic patients.

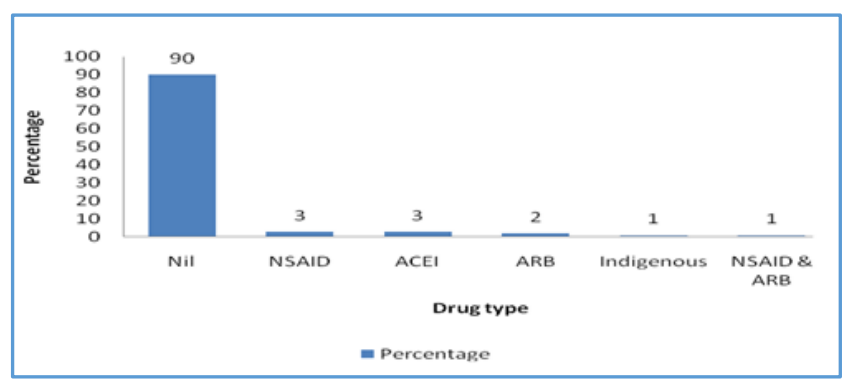

Figure 1

Out of the $10 \%$ of drug induced AKI patients, nonsteroidal anti-inflammatory drugs and angiotensin converting enzyme inhibitors and angiotensin receptor blockers were found to cause AKI.

3. Percentage distribution of accelerated hypertension leading to the development of acute kidney injury in diabetic patients.

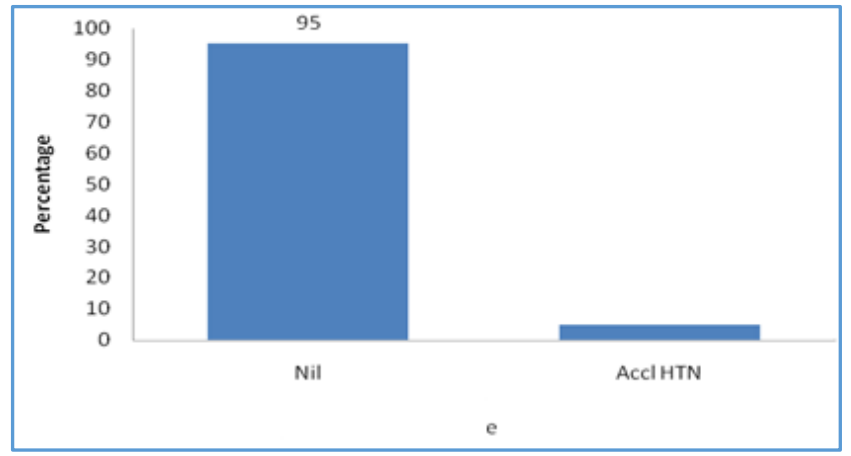

Figure 2

$5 \%$ of AKI cases in diabetics were due to accelerated hypertension 
4. Percentage distribution of CAD/LVD leading to the development of acute kidney injury in diabetic patients.

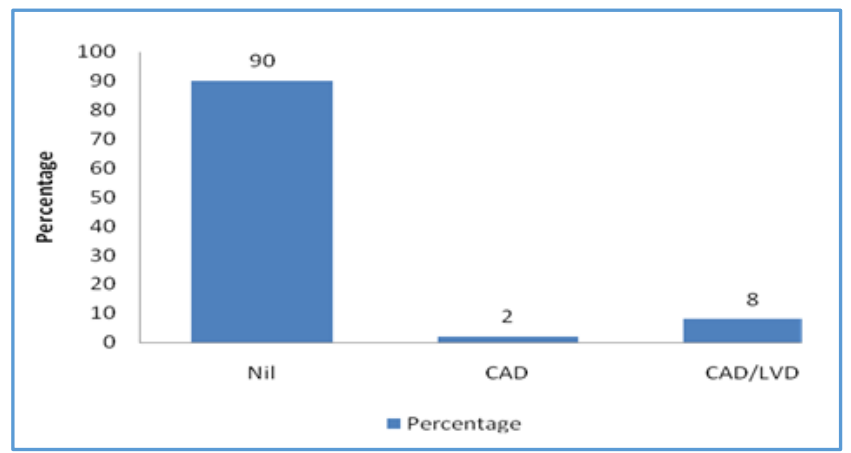

Figure 3

The chance for developing acute kidney injury is increased when CAD is associated with LV dysfunction.

5. Percentage distribution of various infections leading to the development of acute kidney injury in diabetic patients.

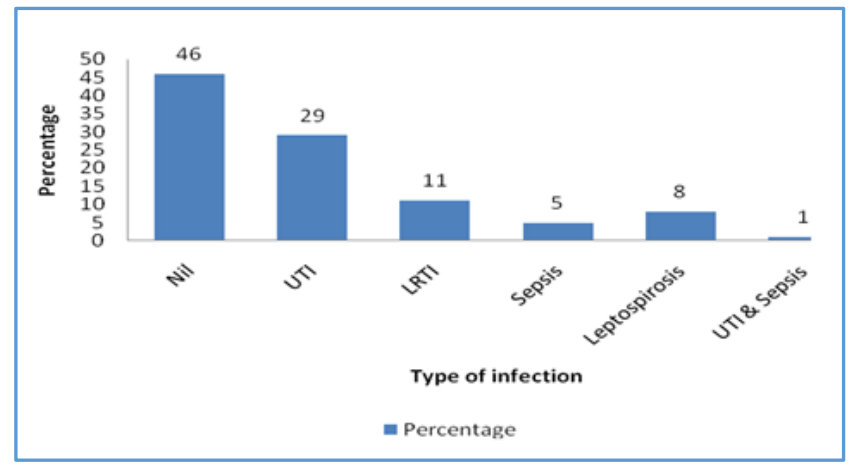

Figure 4

Infections accounted for $54 \%$ of AKI in diabetics. Among this, urinary tract infection was found to be the most common cause of AKI in diabetics.

6. Percentage distribution of various forms of obstruction leading to the development of acute kidney injury in diabetic patients

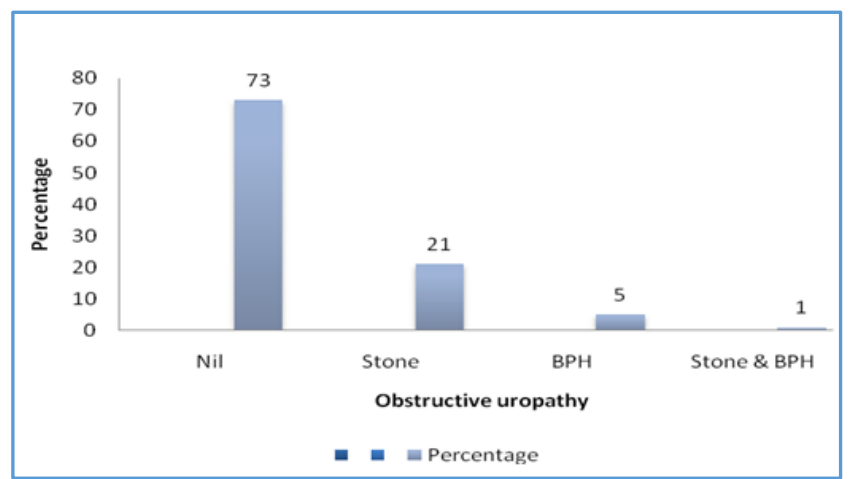

Figure 5
Obstructive uropathy led to the development of AKI in $27 \%$ of diabetic patients, of which $21 \%$ was due to renal stone.

7. Percentage distribution of aetiology of AKI in diabetic patients

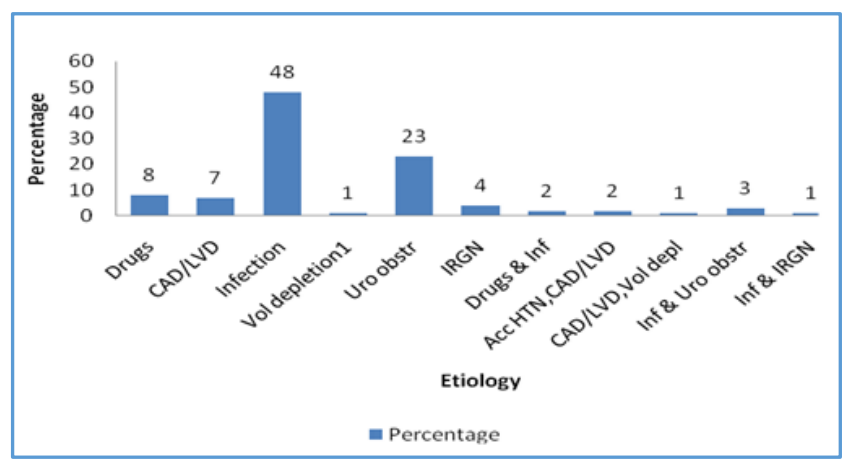

Figure 6

Infections were found to be the most common cause for the development of AKI in diabetic patients. Next was urological obstruction followed by drugs and CAD/LVD.

8. Percentage distribution of outcome of AKI in Type 2 diabetes

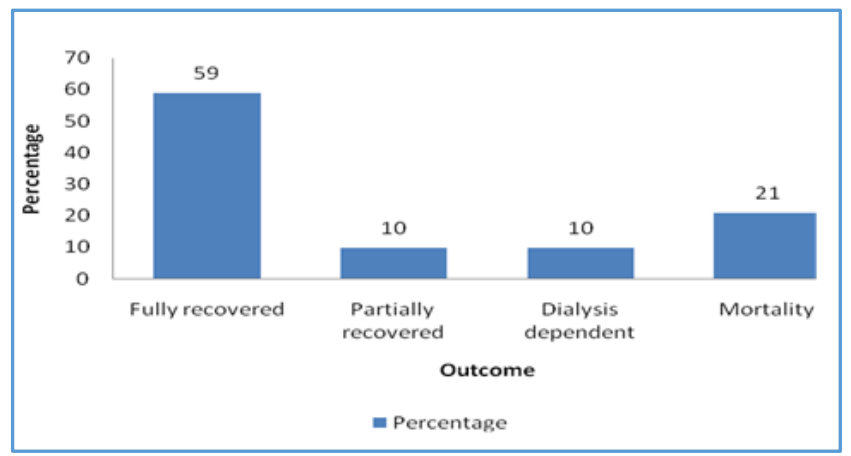

Figure 7

$69 \%$ of the patients in the study had good outome, of which $59 \%$ had full recovery and $10 \%$ had partial recovery. $31 \%$ had poor outcome of which mortality was found to be $21 \%$ and $10 \%$ was put on maintenance hemodialysis (Dialysis dependent).

9. Percentage distribution of mortality with age in diabetic AKI patients

\begin{tabular}{|c|c|c|c|}
\hline Age Group & \multicolumn{2}{|c|}{ Mortality } & P value \\
\hline & Yes & No & \multirow{5}{*}{0.001} \\
\hline$<50$ & $3(14.35 \%)$ & $18(85.7 \%)$ & \\
\hline $50-59$ & $2(5.4 \%)$ & $35(94.6 \%)$ & \\
\hline $60-69$ & $8(26.7 \%)$ & $22(73.3 \%)$ & \\
\hline$>70$ & 7 (58.3\%) & $5(41.7 \%)$ & \\
\hline \multicolumn{4}{|c|}{ Table 2} \\
\hline
\end{tabular}

Mortality was found to be increasing with age. 
10. Mean age of mortality among diabetic AKI patients

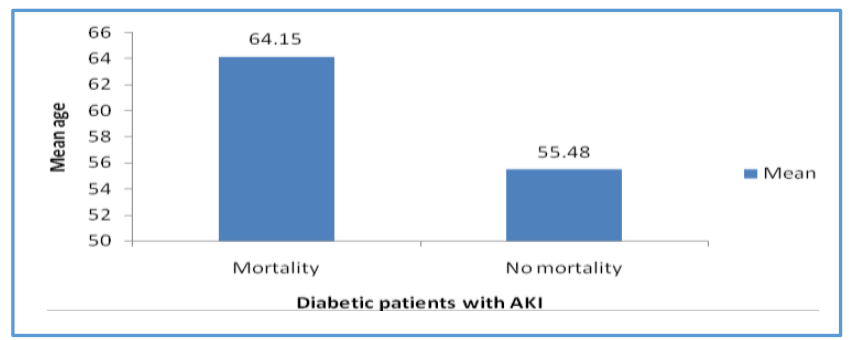

Figure 8

11. Percentage distribution of mortality among male and female diabetic AKI patients

\begin{tabular}{|c|c|c|c|}
\hline Sex & \multicolumn{2}{|c|}{ Mortality } & P value \\
\hline & Yes & No & \multirow{2}{*}{0.096} \\
\cline { 1 - 2 } Male & $16(25 \%)$ & $48(75 \%)$ & \\
\hline Female & $4(11.1 \%)$ & $32(88.9 \%)$ & \\
\hline \multicolumn{4}{|c|}{ Table 3 } \\
\hline
\end{tabular}

Mortality was found to be more among males with diabetic AKI.

12. Percentage distribution of mortality with various infections in diabetic AKI patients

\begin{tabular}{|c|c|c|c|}
\hline Infection & \multicolumn{2}{|c|}{ Mortality } & P value \\
\hline & Yes & No & \\
\cline { 1 - 3 } No infection & $3(6.5 \%)$ & $43(93.5 \%)$ & \\
\hline UTI & $7(24.1 \%)$ & $22(75.9 \%)$ & \multirow{2}{*}{$<0.001$} \\
\hline LRTI & $0(.0 \%)$ & $11(100 \%)$ \\
\hline Sepsis & $2(40 \%)$ & $3(60 \%)$ & \\
\cline { 1 - 3 } Leptospirosis & $7(87.5 \%)$ & $1(12.5 \%)$ \\
\cline { 1 - 2 } UTI \& Sepsis & $1(100 \%)$ & $0(.0 \%)$ & \\
\hline \multicolumn{3}{|c|}{ Table 4 } \\
\hline
\end{tabular}

Leptospirosis and a combination of sepsis \& UTI increased the mortality in diabetic AKI.

13. Percentage distribution of mortality with obstruction in diabetic AKI patients

\begin{tabular}{|c|c|c|c|}
\hline Obstructive Uropathy & \multicolumn{2}{|c|}{ Mortality } & P value \\
\hline & Yes & No & \\
\hline No obstruction & $13(17.8 \%)$ & $60(82.2 \%)$ & \\
\cline { 1 - 3 } Stone & $5(23.8 \%)$ & $16(76.2 \%)$ & \multirow{2}{*}{0.591} \\
\hline BPH & $2(40 \%)$ & $3(60 \%)$ & \\
\hline Stone \& BPH & $0(.0 \%)$ & $1(100 \%)$ & \\
\hline \multicolumn{3}{|c|}{ Table 5 } \\
\hline
\end{tabular}

Among obstructive uropathy, those with BPH had high mortality.

14. Percentage distribution of mortality with aetiology in diabetic AKI patients

\begin{tabular}{|c|c|c|c|}
\hline Aetiology & \multicolumn{2}{|c|}{ Mortality } & \multirow{2}{*}{ P value } \\
\hline & Yes & No & \\
\cline { 1 - 3 } Drugs & $0(.0 \%)$ & $8(100 \%)$ & \multirow{2}{*}{0.001} \\
\hline CAD/LVD & $0(.0 \%)$ & $7(100 \%)$ & \\
\hline Infection & $11(22.9 \%)$ & $37(77.1 \%)$ & \\
\hline Volume depletion & $0(.0 \%)$ & $1(100 \%)$ & \\
\hline
\end{tabular}

\begin{tabular}{|c|c|c|}
\hline Urological obstruction & $3(13 \%)$ & $20(87 \%)$ \\
\hline IRGN & $0(.0 \%)$ & $4(100 \%)$ \\
\hline Drugs \& infection & $2(100 \%)$ & $0(.0 \%)$ \\
\hline Accl HTN \& CAD/LVD & $0(.0 \%)$ & $2(100 \%)$ \\
\hline $\begin{array}{c}\text { CAD/LVD \& volume } \\
\text { depletion }\end{array}$ & $0(.0 \%)$ & $1(100 \%)$ \\
\hline $\begin{array}{c}\text { Infection \& Urological } \\
\text { obstruction }\end{array}$ & $3(100 \%)$ & $0(.0 \%)$ \\
\hline Infection \& IRGN & $1(100 \%)$ & $0(.0 \%)$ \\
\hline \multicolumn{3}{|c|}{ Table 6 } \\
\hline
\end{tabular}

Mortality in diabetic AKI patients was found to be increased when infections were associated with urological obstruction, drugs or IRGN.

\section{Relation of different lab parameters with mortality}

\begin{tabular}{|c|c|c|c|}
\hline & Mortality & No Mortality & P value \\
\hline $\begin{array}{c}\text { Total WBC Count } \\
\text { Mean }\end{array}$ & 15060 & 10985.63 & \multirow[t]{2}{*}{$<0.001$} \\
\hline SD & 3963.969 & 3690.024 & \\
\hline $\begin{array}{c}\text { Platelet Count } \\
\text { Mean }\end{array}$ & 1.5955 & 2.3514 & \multirow[t]{2}{*}{$<0.001$} \\
\hline SD & 0.79759 & 0.81962 & \\
\hline $\begin{array}{l}\text { FBS } \\
\text { Mean }\end{array}$ & 220.8 & 165.29 & \multirow[t]{2}{*}{$<0.001$} \\
\hline SD & 40.963 & 30.123 & \\
\hline $\begin{array}{l}\text { PPBS } \\
\text { Mean }\end{array}$ & 390.4 & 279.09 & \multirow[t]{2}{*}{$<0.001$} \\
\hline SD & 61.711 & 55.132 & \\
\hline $\begin{array}{c}\text { Serum Na } \\
\text { Mean }\end{array}$ & 126.4 & 132.53 & \multirow[t]{2}{*}{$<0.001$} \\
\hline SD & 4.849 & 4.749 & \\
\hline
\end{tabular}

\begin{tabular}{|c|c|c|c|}
\hline $\begin{array}{c}\text { Serum K } \\
\text { Mean }\end{array}$ & Mortality & No mortality & P value \\
\hline SD & 5.4 & 5.003 & \multirow{2}{*}{0.793} \\
\hline $\begin{array}{c}\text { Blood Urea } \\
\text { Base line }\end{array}$ & 88.6316 & 74.5000 & 0.028 \\
\hline Admission & 196.7000 & 134.1375 & 0.000 \\
\hline Discharge & 235.0500 & 94.4000 & 0.000 \\
\hline $\begin{array}{c}\text { Serum } \\
\text { Creatinine } \\
\text { Baseline }\end{array}$ & 4.5632 & 3.4513 & 0.015 \\
\hline Admission & 10.8200 & 11.1338 & 0.935 \\
\hline Discharge & 13.8526 & 5.8363 & 0.000 \\
\hline \multicolumn{3}{|c|}{ Table 7 } \\
\hline
\end{tabular}

\section{DISCUSSION}

Most of the AKI patients in the study were in the age group of 50-59 years with 37\% incidence and 60-69 years with 30\% incidence (Table 1). Similar age group of 51-60 years with $34.3 \%$ incidence was noted in a prospective study of ARF in diabetes mellitus by Vakrani et al.(1) The present study highlights the potential risk of AKI in elderly patients especially above the age of 60 years. The development of AKI in this population could be explained partly as the decline in renal function with age.(6) The increase in mortality with age was found to be statistically significant ( $p$ value 0.001 ).

Infections were found to be the most common cause of AKI in the study. It accounted for $54 \%$ of cases, among which UTI was found in more than half of the cases. In a prospective study by Khan and Ahmed, (7) the most common focus of infection was found to be urinary tract $(71.2 \%)$. 
Sepsis was found to be the most common cause for AKI in several studies.(2,8-11) The lower proportion of sepsis in this study might be attributed to the fact, unlike the above studies, the majority of patients selected for were not critically ill patients from ICU, but from medicine and nephrology wards.

Urinary tract obstruction was the second most common cause in this study that accounted for $23 \%$. Vakrani $t$ al found sepsis $(52.9 \%)$ and urinary tract obstruction $(50 \%)$ as the leading causes for renal failure in diabetics.(1) Jha et al., and Prakash et al., which evaluated AKI had shown that nephrotoxic drugs were the most common cause of AKI.(12,13)

In the present study, drug induced AKI accounted for only $10 \%$ of the cases, which is lower than the above studies. Similarly, drug induced AKI accounted for only $5.6 \%$ of the cases in a study by Eswarappa et al.(2) This might suggest that increasing knowledge of precautions regarding nephrotoxic drugs have helped to reduce the incidence of drug induced AKI. In the present study, NSAIDs were noted to be most common cause of drug induced renal failure with either as unifactorial, or together with other contributory factors as multifactorial (Figure 1). It constituted around $40 \%$ of cases of drug induced renal disease which was followed by ACEI and ARBs.

NSAIDs reversibly inhibit the production of renal prostaglandins via their inhibition of COX-1 and COX-2. Renal prostaglandins cause dilatation of the renal afferent arteriole. This mechanism is important for maintaining GFR when renal blood flow is reduced. Therefore, NSAID use is likely to have a greater effect on renal function in patients with increasing age, pre-existing renal disease, chronic hypertension, heart failure, use of ACEI and ARBs etc. Study conducted by Abdul Ghani et al. also concluded that the commonest drugs that induced AKI were non-steroidal anti-inflammatory drugs (NSAIDs), angiotensin-converting-enzyme inhibitors and angiotensin-receptor blockers.(14) In Arrizabalaga study, nonsteroidal anti-inflammatory drugs were the most frequent etiology in $44 \%$ of cases of drug induced renal disease.(15)

In the study by Prakash et al, $47 \%$ patients recovered from renal failure with appropriate institution of treatment.(4) In this study, recovery was found in $64.3 \%$. Our findings are in agreement with a review study by Rodrigo et al., which demonstrated a significantly increased risk of AKI in critically ill patients with older age, diabetes, hypertension, higher baseline creatinine, heart failure, sepsis, use of nephrotoxic drugs.(16) The association between higher creatinine levels and risk for AKI was also reported by Charuhas et al.(5)

In this study, $69.0 \%$ of the patients recovered normal renal function (Figure 7). Similarly, studies by Eswarappa et $\mathrm{al}^{(2)}$ and Vakrani et al(1) showed a recovery rate of $60 \%$ and $64.3 \%$ respectively. Excluding the patients who passed away, the percentage of complete renal recovery was $75 \%$ among the survivors. Complete renal recovery is less commonly reported in the literature, however few studies have previously shown that the majority of patients recover sufficient renal function with one study even showing $68.0 \%$ of patients recovered completely. $(8,3)$ The excellent recovery seen in the present study, might be due to the exclusion of patients with preexisting renal disease. Schiffl, in his study showed that if critically ill patients with normal renal function prior to the renal insults, survive the precipitating cause of ATN, the overwhelming majority will recover sufficient renal function.(17)
Mortality rate in this study was $21 \%$ (Figure 7). The crude in-hospital mortality rate reported by Sushrut S. Waikar et al was $25 \%$ (18). The mortality rate in the present study was less compared to that by Eswarappa et al (37.6\%), Ali et al. $(32.7 \%)$ and Joaniddis et al. (36.5\%).(2,8,19) In general AKI in critically ill patients is considered an independent risk factor for an increased morbidity, mortality. The lower mortality rate in our study might be due to the fact that the patients selected for our study did not have preexisting renal disease, better haemodialysis support and better patient care in our institution.

The risk for mortality was found to be increased with increasing age (Table 2), male sex (Table 3), sepsis with UTI (Table 4), BPH (Table 5), increased mean blood urea (Table 7) and serum creatinine levels (Table 7). Similar results were found in studies of Eswarappa et al.(2)

Mortality was also found to be increased in patients with high mean FBS, PPBS, total WBC counts and serum potassium, and low serum sodium and platelet counts. (Table 7)

The increase in awareness of these risk factors will help in the early identification of kidney injury that is critical for treatment or prevention of AKI.

\section{Limitations of the Study}

1. Larger sample size could yield more conclusive data and results.

2. The study was conducted among patients admitted to ICU, Medicine and Nephrology wards. Hence the study population does not represent the general population.

3. Diabetic status was assessed based on previous medical history and FBS, PPBS values, so we did not have information on HBA1C levels or exhaustive diabetes complications.

4. AKI was diagnosed according to the KGDIGO guidelines but only based on serum creatinine variations, as urinary output was not available in the database.

\section{CONCLUSION}

1. Infection was the most common cause of AKI in Type 2 diabetes patients in our study.

2. Among drug induced renal failure patients, NSAIDS were noted to be most common cause.

3. Age $>60$ and male gender were prevalent in the majority of AKI patients.

4. About $59 \%$ of the total patients recovered to normal renal function, $10 \%$ recovered partially, with $10 \%$ of the total patients progressed for maintenance hemodialysis.

5. Crude mortality rate among patients with AKI in the study group was $21 \%$.

\section{REFERENCES}

[1] Vakrani GP, Ramakrishnan S, Rangarajan D. Acute renal failure in diabetes mellitus (Prospective study). J Nephrol Ther 2013;3(3):137.

[2] Eswarappa M, Gireesh MS, Ravi V, et al. Spectrum of acute kidney injury in critically ill patients: a single center study from South India. Indian J Nephrol 2014;24(5):280-5.

[3] Levy EM, Viscoli CM, Horwitz RI. The effect of acute renal failure on mortality: a cohort analysis. JAMA 1996;275(19):1489-94. 
[4] Prakash J, Sen D, Usha, et al. Non-diabetic renal disease in patients with type 2 diabetes mellitus. J Assoc Physicians India 2001;49:415-20.

[5] Thakar CV, Christianson A, Himmelfarb J, et al. Acute kidney injury episodes and chronic kidney disease risk in diabetes mellitus. Clin J Am Soc Nephrol 2011;6(11):2567-72.

[6] Glassock RJ, Rule AD. The implications of anatomical and functional changes of the aging kidney: with an emphasis on the glomeruli. Kidney Int 2012;82(3):270-7.

[7] Khan FG, Ahmed E. Acute renal failure in diabetes mellitus. J Pak Med Assoc 2015;65(2):179-82.

[8] Ali T, Khan I, Simpson W, et al. Incidence and outcomes in acute kidney injury: a comprehensive population-based study. J Am Soc Nephrol 2007;18(4):1292-8.

[9] Bagshaw SM, Uchino S, Bellomo R, et al. Septic acute kidney injury in critically ill patients: clinical characteristics and outcomes. Clin J Am Soc Nephrol 2007;2(3):431-9.

[10] Singbartl K, Kellum JA. AKI in the ICU: definition, epidemiology, risk stratification and outcomes. Kidney Int 2012;81(9):819-25.

[11] Mahajan S, Tiwari S, Bharani R, et al. Spectrum of acute renal failure and factors predicting its outcome in an intensive care unit in India. Ren Fail 2006;28(2):11924.
[12] Jha V, Malhotra HS, Sakhuja V, et al. Spectrum of hospital-acquired acute renal failure in the developing countries - Chandigarh study. Q J Med 1992;83(303):497-505.

[13] Prakash J, Singh SP, Kumar OM, et al. Hospital acquired acute renal failure. Indian J Nephrol 1996;6:9-13.

[14] Ghani AR, Zainudin S, Kamaruddin NA, et al. Acute renal failure following the use of rosiglitazone in a chronic kidney disease patient. Singapore Med J 2009;50(1):e32-4.

[15] Clemente PA. Feminisation and nephrology. Nefrologia 2010;30(1):110-3.

[16] Cartin-Ceba R, Kashiouris M, Plataki M, et al. Risk factors for development of acute kidney injury in critically ill patients: a systematic review and metaanalysis of observational studies. Article ID 691013 , Crit Care Res Pract 2012;2012: p. 15.

[17] Schiffl H. Renal recovery from acute tubular necrosis requiring renal replacement therapy: a prospective study in critically ill patients. Nephrol Dial Transplant 2006;21(5):1248-52.

[18] Waikar SS, Liu KD, Chertow GM, et al. The incidence and prognostic significance of acute kidney injury. Curr Opin Nephrol Hypertens 2007;16(3):227-36.

[19] Joannidis M, Metnitz B, Bauer P, et al. Acute kidney injury in critically ill patients classified by AKIN versus RIFLE using the SAPS 3 database. Intensive Care Med 2009;35(10):1692-702. 